\title{
Barriers to and Facilitators of Physical Activity Program Use Among Older Adults
}

\author{
Hilary J. Bethancourt, MA; Dori E. Rosenberg, PhD, MPH; Tara Beatty, MA;
} and David E. Arterburn, MD, MPH

\begin{abstract}
Objective: Regular physical activity (PA) is important for maintaining long-term physical, cognitive, and emotional health. However, few older adults engage in routine PA, and even fewer take advantage of programs designed to enhance PA participation. Though most managed Medicare members have free access to the Silver Sneakers and EnhanceFitness PA programs, the vast majority of eligible seniors do not utilize these programs. The goal of this qualitative study was to better understand the barriers to and facilitators of PA and participation in PA programs among older adults.
\end{abstract}

Design: This was a qualitative study using focus group interviews.

Setting: Focus groups took place at three Group Health clinics in King County, Washington.

Participants: Fifty-two randomly selected Group Health Medicare members between the ages of 66 to 78 participated.

Methods: We conducted four focus groups with 13 participants each. Focus group discussions were audio-recorded, transcribed, and analyzed using an inductive thematic approach and a social-ecological framework.

Results: Men and women were nearly equally represented among the participants, and the sample was largely white $(77 \%)$, well-educated (69\% college graduates), and relatively physically active. Prominent barriers to PA and PA program participation were physical limitations due to health conditions or aging, lack of professional guidance, and inadequate distribution of information on available and appropriate PA options and programs. Facilitators included the motivation to maintain physical and mental health and access to affordable, convenient, and stimulating PA options.

Conclusion: Older adult populations may benefit from greater support and information from their providers and health care systems on how to safely and successfully improve or maintain PA levels through later adulthood. Efforts among health care systems to boost PA among older adults may need to consider patient-centered adjustments to current PA programs, as well as alternative methods for promoting overall active lifestyle choices.

Keywords: Barriers; Exercise; Older adults; Physical activity programs; Qualitative research

Corresponding Author: Hilary J. Bethancourt, MA; University of

Washington; Department of Anthropology; P.O. Box 353100; Seattle, WA

98195; Email: hilaryjb@u.washington.edu
Received: April 16,2013

Revised: August 3, 2013

Accepted: August 7, 2013

doi: $|0.3| 2|/ \mathrm{cmr} .20| 3 .|| 7 \mid$ 
$\mathrm{D}$ espite the well-known importance of physical activity (PA) in the maintenance of physical, cognitive, and emotional health through the later adult years, ${ }^{1-3}$ older adults remain the least active age group in the United States. ${ }^{3-6}$ Less than a third of older adults in the United States report meeting recommended PA levels in national surveys, ${ }^{4}$ and accelerometer-measured PA levels provide an even more alarming statistic $(<4 \%)^{7}$ Not only is inactivity a major contributor to the growing burden of non-communicable diseases in the United States and worldwide, ${ }^{8}$ but it also has major implications for the ever-increasing health care costs attributed to these diseases. ${ }^{9-11}$ With medical expenditures already being highest among older adults ${ }^{12}$ and the proportion of the United States population aged 65 and older expected to double over the next four decades, ${ }^{13}$ promoting PA among older adults is an important public health, clinical, and economic issue deserving greater attention.

In recognition of this looming problem, some health plans have begun to offer their older beneficiaries free or low-cost access to community-based PA programs. For example, some Medicare Advantage members can participate in two nationally disseminated, community-based PA programs free of charge: 1) Silver Sneakers (SS), which covers membership to conditioning classes, exercise equipment, and other amenities of local participating fitness centers; and 2) EnhanceFitness (EF), an evidence-based group exercise program designed specifically to fit the needs of older adults. ${ }^{14,15}$ Studies have shown that participation in these programs has the potential to decrease (or at least attenuate the rate of increase in) total annual health care expenditures in both the general population ${ }^{16,17}$ and in patients with diabetes. ${ }^{18,19}$ However, these reductions in health care costs, mostly attributed to fewer hospital admissions and lower in-patient care costs, are generally observed among users only after continued use for more than one year ${ }^{17}$ or with attendance of more than once a week for the EF program ${ }^{16,18}$ and more than twice a week for the SS program. ${ }^{17,19}$ Notably, past reports have found that only about $25 \%$ of eligible members are actually enrolled in either EF or SS, and even fewer utilize the programs regularly (at least once a month) or continue with the programs in subsequent years. ${ }^{17}$

No known studies have examined barriers to the utilization of these two PA programs among eligible older adults in the context of a health care setting. The aforementioned studies on EF and SS programs were based on administrative and accounting data and were not able to determine if nonparticipants were active in other ways (eg, not interested in the programs) nor able to assess the potential psychological, social, environmental, and organizational impediments and enablers to program participation. One study did investigate underutilization of similar kinds of PA programs and services offered to independent residents of a Maryland retirement community. ${ }^{20}$ Those participants described the ideal PA program as convenient, easily accessible (in location and cost), enjoyable, social, and run by knowledgeable staff. That study did not address whether the current programs lacked these characteristics or what the specific barriers to existing programs and services were. A review of 15 qualitative and 29 quantitative studies on barriers and motivators to general PA among older adults indicated that health concerns were the most prominent factor influencing PA engagement. ${ }^{21}$ Another review of prospective and intervention studies noted that health status was an important determinant of initiation and maintenance of PA among older adults. ${ }^{22}$ Apart from health impediments and motivators, other prominent factors associated with general PA have included fear of injury or pain, self-motivation, lack of time, enjoyment of PA, social support, neighborhood conditions, weather, expense, accessibility and convenience of classes and facilities, and characteristics related to self-efficacy, such as confidence, expectations, perceived support, and affective responses related to PA. ${ }^{20-23}$

The objective of this study was to gain further insight into barriers to and facilitators of both general PA and participation in PA programs, such as the EF and SS programs. Qualitative methods were chosen to obtain a patient-centered perspective. Moreover, we aimed to gain a better understanding of participants' perceptions of the role of health care systems in supporting and encouraging PA. Our goal was to generate a set of recommendations for potential organizational-level changes that may promote increased PA among older adults.

\section{Methods}

\section{Recruitment}

All procedures for this study were approved by the Human Subjects Review Committee of Group Health Research Institute. Adults between the ages of 66 and 80 years were recruited from Group Health, an integrated health care system serving the Pacific Northwest with over 600,000 members, of whom roughly 50,000 are aged 65 and older. We randomly selected a sample of 415 members at three clinics in King County, Washington who met the following general eligibility criteria by electronic health record data: community dwelling (eg, not residing in skilled nursing facility); no serious physical or mental health diagnosis (eg, recent cancer diagnosis, in hospice care, dementia, serious mental health disorder); and continuously enrolled in a Medicare plan for the previous 12 months. The majority of Group Health Medicare members ( $90 \%$ ) have a Medicare Advantage plan that covers EF and SS participation with no cost to the participant. Non-Medicare advantage plan members can still attend EF classes for a low fee. We stratified sampling by use of senior fitness programs to ensure a mixture of program users and non-users. We identified people as users vs. nonusers by merging program data from EF and SS with electronic health record data. People were considered users if they had been to a SS facility or EF class at least two times within the year. 


\section{Procedures}

We mailed invitational letters requesting that those interested in participating call a study phone line. A research assistant returned all phone calls, screened for eligibility, answered questions about the study, and provided further information about the focus group if the caller agreed to attend. Additional eligibility criteria included ability to attend the focus group date and time, ability to walk one block with or without an assistive device, and ability to read and speak English. Out of 415 letters mailed, $15 \%(\mathrm{~N}=62)$ responded to the mailing with interest in participating. Three were ineligible and seven were placed on a wait list as the focus group had already been filled. A total of 13 participants attended each focus group (total $\mathrm{N}=52$ ).

At the focus group, participants provided written consent and completed a brief survey before the focus group. A court reporter transcribed all focus group content verbatim. A digital recorder was also employed for back-up purposes. The recordings were reviewed and compared to the transcript provided by the court reporter. Several small discrepancies (which did not change the meaning of the discussion) were noted and fixed prior to data analysis.

The lead facilitator for three of the four focus groups (DER) has a background in clinical psychology, public health, and aging. She had previous experience conducting focus groups with older adults and obtained further guidance from local faculty with expertise in qualitative research design and data analysis. The other facilitator (HJB) was a doctoral student in anthropology and master's student in public health who had observed one focus group and received training from the lead facilitator and other faculty members. The lead facilitator was available for the duration of this focus group to assist and ensure smooth operations. Both facilitators followed a semistructured interview guide consisting of six open-ended questions (See Appendix A for list of complete questions). Questions covered views on the importance of PA, the types of PA support available from their health care system, and views on the senior fitness program benefits.

\section{Participants}

Two of the four focus groups were comprised of participants who had no record of attending a senior fitness program. One group consisted entirely of senior fitness program users, and the other group was predominantly non-users (3/13 had used the program at least twice).

\section{Senior Fitness Programs}

The SS program provides Medicare Advantage enrollees access to fitness facilities at over 10,000 locations across the United States. Participants can access the gym, like any other type of gym membership, to use equipment or attend any classes that are offered at the facility. In addition, group-based $\mathrm{SS}$ classes are offered at facilities. The EF program is a group-based exercise program for community-dwelling older adults ${ }^{14,15}$ and is offered at various community sites throughout
Western Washington including senior centers, retirement facilities, and health care clinics. There are about 50 sites that offer EF in King County. Classes are taught by certified instructors and are adaptable to the functional abilities of older adults. They follow a standardized format including a 5 minute warm up, 20-25 minutes of moderate-intensity aerobics, 20 minutes of resistance strength training, and 10 minutes of flexibility and balance exercises. ${ }^{16}$

\section{Survey and Survey Analysis}

The brief survey administered prior to each focus group included a measure of self-reported PA using the short version of the International Physical Activity Questionnaire (IPAQ) ${ }^{24}$ and an additional question on time spent watching television. It also included questions on PA preferences, use of PA programs, self-reported health status, and demographic and health characteristics (age, sex, height, weight, race/ethnicity, highest level of education completed, employment status, marital status, transportation modes, and use of an assistive device). The IPAQ was scored according to the guidelines, ${ }^{25}$ and participants were classified by whether they reported obtaining the 150 minutes or more of moderate or 75 minutes or more of vigorous PA during the previous week. No existing measures of PA preferences were available, so the lead researcher developed items asking about preferences for doing PA with family or friends, at home, in the neighborhood, in a class with others of the same age, or in a class/group with people of any age. Response options were on a 4-point Likert scale (strongly disagree, somewhat disagree, somewhat agree, strongly agree). Results are reported as the percent of participants stating that they somewhat or strongly agreed with each statement. Self-reported health was elicited using the SF-1 rating of health (poor, fair, good, very good, or excellent). ${ }^{26}$ Other demographic and health characteristics are reported as sample means and proportions.

\section{Qualitative Data Analysis}

Coding was completed following an inductive thematic approach, ${ }^{27}$ which involved a process of identifying distinguishable patterns in the concepts and ideas that emerged from participants' statements. To reduce the degree of subjective projection in the analysis, all transcripts were coded independently by the two individuals who led the focus groups. An initial review of the transcripts allowed the two coders to create a baseline code list. The codes were further refined through an iterative process of successive rounds of independent reviews of transcripts and meetings to identify discrepancies between coders and make codebook revisions. A third team member helped resolve discrepancies and review adequacy of code lists, and the project team reviewed findings and offered feedback. An audit trail was kept detailing all coding definitions and decisions rules and was updated throughout the coding process.

All final codes were entered into ATLAS.ti 6.2 so that all relevant quotes related to each code could be reviewed. The analysis revealed several overarching themes that fit well 
within a social-ecological framework ${ }^{28-30}$ representing domains of intrapersonal, interpersonal, social, built environment, and structural/organizational barriers and facilitators. Thus, the themes were categorized accordingly within each of these levels of influence. To ensure the accuracy and credibility of the coding process, we employed member checking of the themes by all focus group participants as well as two delivery system partners that administer the programs.

\section{Results}

\section{Survey Results}

Participants $(\mathrm{N}=52)$, ages 66 to 78 , were primarily Caucasian, retired, married, had a college or graduate degree, had good to excellent self-rated health, and had high self-reported levels of PA (see Table 1). Only $28.9 \%$ of those who answered all of the IPAQ questions did not report PA levels that meet current recommendations. ${ }^{31}$ Most participants had heard of EF or SS (86\%), but only $20 \%$ and $40 \%$ had actually used EF and SS programs, respectively. Few were encouraged to attend by a physician. Regarding preferences for PA, 86\% agreed that they preferred doing PA in their home neighborhood, and $71 \%$ preferred doing PA with family and friends. Though $65 \%$ agreed to the statement regarding preference for a class or PA group with people their age, $63 \%$ also agreed to the statement of preferring PA in a class or group with people of any age. About 53\% said they do PA at a gym or fitness facility, while $28 \%$ reported they prefer doing PA at home.

\section{Focus Group Results}

Intrapersonal factors: Having physical limitations was frequently noted as an individual-level barrier to PA (Table 2). This manifested as specific ailments or injuries among some, such as the participant who mentioned: "Because I have deep vein thrombosis, it's very difficult to work on hills and stairs" (participant 3). Among others, it was the general aging-related aches and pains and prolonged recovery time that limited their PA. One participant stated, "I used to do a lot more actually, but as my body breaks down... it takes longer to recover, so I don't do that anymore than I have to" (participant 1). For some, the awareness of their physical limitations also translated into a fear of falling, recognizing that they were more vulnerable to falls and would have a more difficult time recovering from a fall.

Conversely, some viewed PA as a way to deal with specific health conditions. For example, one participant shared, "Eighteen years ago, I was diagnosed with MS... and I started to exercise...I have to stay active to keep from regressing. And if I don't exercise on a regular basis, you know, if I skip a week, I feel like I've lost, and it takes me another 2 weeks to gain where I was" (participant 11). For others, knowing PA could help them to maintain the strength, energy, and agility
Table 1. Sample demographics and use of PA programs.

\begin{tabular}{|c|c|}
\hline Age: Mean (SD, range) & $70.9(3.7,66-78)$ \\
\hline Body Mass Index: Mean (SD, range) & $27.4(5.7 ; 18.7-48.8$ \\
\hline Female: $\mathrm{N}(\%)$ & $28(54.0 \%)$ \\
\hline \multicolumn{2}{|l|}{ Race/ethnicity: N (\%) } \\
\hline American Indian/Alaska Native & $2(3.8)$ \\
\hline Asian & $7(13.5)$ \\
\hline Black/African American & $2(3.8)$ \\
\hline White/Caucasian & $40(77.0)$ \\
\hline \multicolumn{2}{|l|}{ Education: N (\%) } \\
\hline High school or less & $3(5.8)$ \\
\hline Vocational, technical, trade school & $3(5.8)$ \\
\hline Some college & $10(19.2)$ \\
\hline College graduate & $13(25.0)$ \\
\hline Graduate or Professional degree & $23(44.2)$ \\
\hline \multicolumn{2}{|l|}{ Employment: $\mathrm{N}(\%)$} \\
\hline Retired & $42(81.8)$ \\
\hline Employed part-time & $7(13.5)$ \\
\hline \multicolumn{2}{|l|}{ Marital status: $\mathrm{N}(\%)$} \\
\hline Single, widowed, divorced & $17(32.7)$ \\
\hline Married & $35(67.3)$ \\
\hline \multicolumn{2}{|l|}{ Assistive device: N (\%) } \\
\hline Cane, walker or other device & $6(11.5)$ \\
\hline \multicolumn{2}{|l|}{ Self-reported health status: } \\
\hline Excellent & $12(23.1)$ \\
\hline Very good & $21(40.4)$ \\
\hline Good & $10(19.2)$ \\
\hline Fair or poor & $9(17.3)$ \\
\hline \multicolumn{2}{|l|}{ Use of PA Programs: N (\%) ${ }^{*}$} \\
\hline Ever heard of EF or SS & $43(86.0)$ \\
\hline Ever used EF & $10(20.0)$ \\
\hline Ever used SS & $20(40.0)$ \\
\hline Been encouraged to go & $23(46.0)$ \\
\hline Encouraged by physician & $5(10.0)$ \\
\hline Meeting Physical activity Guidelines: N (\%) & $32(71.1)$ \\
\hline $\begin{array}{l}\text { Television-watching time: mean minutes/day } \\
\text { (SD) }\end{array}$ & $145.4(116.3)$ \\
\hline \multicolumn{2}{|c|}{$\begin{array}{l}(N=52 \text { unless otherwise noted }) \\
\text { "N }=50 \\
+N=45 \\
\text { 'Self-reported } 150 \text { minutes/week or more of moderate-intensity or } 75 \text { minutes/week or } \\
\text { more of vigorous-intensity physical activity on the International Physical Activity } \\
\text { Questionnaire - Short Form.24 } \\
\text { PA = physical activity; EF = EnhanceFitness; SS = Silver Sneakers }\end{array}$} \\
\hline
\end{tabular}

to perform daily tasks and other activities they enjoyed motivated them to stay active. One participant noted, "[Physical activity is] top of line for me. I'm a big advocate of it...because I feel so much better, I'm stronger, and I can do more. And I don't have aches and pains. I get sore when I exercise, but it's muscle soreness. It's not an injury or anything. I don't wake up sore. I just have more energy" (participant 36). A number of participants expressed the motivation to maintain a daily PA regime in order to stay fit for their favorite sports or for keeping up with grandchildren. Furthermore, several participants spoke about having learned that PA is beneficial to memory, mood, and cognitive acuity: "And everything I pick up and read says the more physically active you are, the better it is for your mental acuity and facilities, so that's really important to us" (participant 8). Some also spoke from experience, stating that PA helped 
Table 2. List of barriers to and facilitators of physical activity and program participation based on a social-ecological framework.

\begin{tabular}{|c|c|}
\hline BARRIERS & FACILITATORS \\
\hline \multicolumn{2}{|c|}{ INTRAPERSONAL LEVEL FACTORS } \\
\hline \multicolumn{2}{|c|}{ Physical or Mental Health } \\
\hline $\begin{array}{ll}\text { - } & \text { Pain } \\
\text { - } & \text { Decreased endurance and balance } \\
\text { - } & \text { Increased recovery time } \\
\text { - } & \text { Risk of injury } \\
\text { - } & \text { Fear of falling } \\
\end{array}$ & $\begin{array}{l}\text { - } \quad \text { Potential prevention of health problems } \\
\text { - } \quad \text { Management of existing conditions } \\
\text { - } \quad \text { Potential weight loss } \\
\text { - } \quad \text { Mood boost }\end{array}$ \\
\hline \multicolumn{2}{|c|}{ Individual Preferences } \\
\hline $\begin{array}{ll}\text { - } & \text { Dislike of PA, gyms/indoor PA } \\
\text { - } & \text { Dislike of organized/group PA } \\
\text { - } & \text { Lack of motivation } \\
\text { - } & \text { Intimidation/embarrassment } \\
\text { - } & \text { Unsure of appropriate PA } \\
\text { - } & \text { Preference for sedentary activities } \\
\text { - } & \text { Boredom with PA } \\
\text { - } & \text { Not accustomed to doing PA }\end{array}$ & $\begin{array}{ll}\text { - } & \text { Enjoyment of PA } \\
\text { - } & \text { Belief that PA is important } \\
\text { - } & \text { Feeling guilty when not active } \\
\text { - } & \text { Awareness of benefits } \\
\text { - } & \text { PA as part of a routine } \\
\text { - } & \text { Sense of self-efficacy } \\
\text { - } & \text { Proactive pursuit of programs } \\
\text { - } & \text { Daily activities provide PA } \\
\text { - } & \text { PA combined with enjoyable/useful activities }\end{array}$ \\
\hline \multicolumn{2}{|c|}{ INTERPERSONAL LEVEL FACTORS } \\
\hline $\begin{array}{ll}\text { - } & \text { Lack of guidance from a professional } \\
\text { - } & \text { Not motivated by instructors } \\
\text { - } & \text { Not receiving or able to access information on PA } \\
\text { - } & \text { programs } \\
\text { - } & \text { Peing pushed too hard } \\
\end{array}$ & $\begin{array}{ll}\text { - } & \text { Encouragement from others } \\
\text { - } & \text { Companionship of others } \\
\text { - } & \text { Guidance from a professional } \\
\text { - } & \text { Social contact } \\
\text { - } & \text { Others as role models or incentives } \\
\text { - } & \text { Support from dog companions } \\
\end{array}$ \\
\hline \multicolumn{2}{|c|}{ PHYSICAL ENVIRONMENT FACTORS } \\
\hline $\begin{array}{ll}\text { - } & \text { Hills and stairs } \\
\text { - } & \text { Uneven sidewalks } \\
\text { - } & \text { Bad weather } \\
\text { - } & \text { Unsafe neighborhood } \\
\text { - } & \text { PA location not aesthetically pleasing } \\
\text { - } & \text { Inconvenient PA locations } \\
\text { - } & \text { Difficult parking }\end{array}$ & $\begin{array}{ll}\text { - } & \text { Living in a walkable area } \\
\text { - } & \text { Proximity of stores } \\
\text { - } & \text { Places to rest } \\
\text { - } & \text { Even walking surfaces } \\
\text { - } & \text { Alternatives in bad weather } \\
\text { - } & \text { PA options at home } \\
\text { - } & \text { Convenient/nearby PA locations } \\
\text { - } & \text { Pleasurable weather }\end{array}$ \\
\hline \multicolumn{2}{|c|}{ STRUCTURAL AND ORGANIZATIONAL FACTORS } \\
\hline $\begin{array}{ll}\text { - } & \text { Expense to drive to or use facilities } \\
\text { - } & \text { Limited SS and EF facilities } \\
\text { - } & \text { Being ineligible for SS and EF } \\
\text { - } & \text { Inadequate information } \\
\text { - } & \text { Lack of quality instructors } \\
\text { - } & \text { Programs that are not engaging or too challenging } \\
\text { - } & \text { Providers who are not knowledgeable about } \\
& \text { programs }\end{array}$ & $\begin{array}{ll}\text { - } & \text { Free, low-cost programs } \\
\text { - } & \text { High-quality instructors } \\
\text { - } & \text { Flexible program schedule } \\
\text { - } & \text { Engaging classes } \\
\text { - } & \text { Programs appropriate for different fitness levels and } \\
\text { - } & \text { physical limitations } \\
& \text { Distribution of information }\end{array}$ \\
\hline
\end{tabular}

${ }^{*}$ SS = Silver Sneakers; EF = EnhanceFitness; PA = physical activity

them to relax, clear their mind, maintain a healthy outlook on life, or even provide mental stimulation.

Other important intrapersonal factors, particularly regarding the use of PA programs, included personal preferences, likes/ dislikes, intimidation, and personal history with PA. For example, some participants did not like gyms and/or group activities that made them feel embarrassed by their appearance. Some were discouraged by the competitive atmosphere of gyms and group activities or were apprehensive about not being able to keep a comfortable pace or potentially slowing down the group. Moreover, some participants were unmotivated by the notion of doing activity without a purpose or were not interested in exercise for the sake of exercise. One person reported, "I have to force myself to go to the gym, I don't have to force myself to dance" (participant 20).

Other barriers to PA in general included dislike for or disinterest in exercise and/or a preference for sedentary 
leisure-time activities: "It's like taking medicine, I don't enjoy it" (participant 43). Some were able to overcome personal preference barriers by forcing themselves to do PA, because they recognized its importance in maintaining health and physical function: 'I'm in the camp where I hate doing it, but I do it" (participant 43). Some mentioned a generational barrier because exercise per se was not as common when they were growing up. One person noted, "Some of us ladies were born at a time where girls didn't sweat" (participant 23), while another said, "When I was younger, I played a lot of ball, but nobody ever exercised" (participant 26).

Interpersonal factors: Though a number of participants expressed a preference for solitary activities, many felt that group activities and social interaction in exercise classes were important motivators and enablers to engage in PA and attend group-based programs like EF. For some this motivation came from the sense of community and camaraderie in group classes and the incentive to "stay until the end" of a class (participant 31). An important aspect of this included having a fun, knowledgeable, and motivating class instructor: "It's got to be the right instructor for me; that's real important" (participant 24). The merging of PA and social interaction helped some overcome the intrapersonal barriers, as noted by one participant who, through social dancing, is able to "get exercise without thinking [she is] exercising" (participant 20). Some expressed fear or lack of discipline to do PA alone but were motivated by having a group with which to be active. One participant provided an analogy: "It's just like singing - if somebody else knows the tune, I can sing great. But if I'm not following somebody, it doesn't usually happen" (participant 45). People in group classes also served as role models, as one participant mentioned: "I was amazed at the number of women in their 80 s that still do pretty strenuous exercise...that's such a good role model for me to see that and know that I can do it" (participant 31).

Even for those who were not particularly fond of fitness classes, social support was an important facilitator for PA. A number of participants discussed having spouses, family members, or friends who would "coax" them to join them on walks or other group-based activities. Family members were also indirect motivators for some who described the desire to be around for and/or keep up with their family members as an incentive to maintain an active lifestyle and stay in shape. Also worth noting was the fact that several participants mentioned their dogs as a reason they got out and walked regularly.

Just as encouragement from others could be a facilitator of PA, unsolicited guidance from others could serve as a barrier to PA. One participant stated, "The fastest way to discourage me from exercising is to be told to go exercise" (participant 3). Also, overly-aggressive trainers who pushed participants to do more than their bodies could handle were a barrier. One participant, for instance, told of a personal trainer who pushed her so hard that she eventually "lost interest completely" in those exercises (participant 27). At the same time, however, lack of guidance was a prominent barrier for many participants, who expressed disappointment that their health care provider either never initiated a conversation about PA or merely gave the recommendation to engage in PA while offering little or no follow-up nor advice on safe PA given patients' age, fitness level, and physical limitations. Some felt their providers were not adequately trained to give advice on safe exercise for older adults. Yet, many had received the message to "talk to your doctor before you start a physical activity program" and wished they "got more input as individuals from [their] doctors and physical therapists" (participant 17). They also expressed a need for "better guidance of how much [to] exert [oneself]" as opposed to just being told to "go for it" (participant 40). Many participants also demonstrated interest in their providers helping them to track their PA progress.

Factors related to the physical environment: As walking was the most commonly reported PA by focus group participants, weather was an important factor in PA behavior: "I'm kind of a sunshine walker. When it's raining, I'm not so good at it" (participant 4). Additionally, having easy access to safe, aesthetically pleasing, and interesting places to walk with flat, even surfaces and available resting spots was valued: "Because my legs start hurting...I have to sit periodically. The places I do my walking, I know where all the places to sit are" (participant 3). People expressed appreciation for parks and opportunities for mall walking. Hills, stairs, uneven walking surfaces, and rainy weather were prominent built environment barriers. Participants conveyed the importance of having clean, conveniently and proximately located fitness facilities with easily accessible and maneuverable parking space: "[My gym] is really close to where I live. I think that will always be important to me, that it's close. The closer, the more likely I'll go" (participant 42).

Structural and organizational factors: Convenience was important not only in terms of location, but also in terms of class offerings: "I wouldn't be going to class at all if it weren't convenient, if it weren't something that I could walk to, and it [weren't] at a convenient hour...I do it because it's been made easy for me to do" (participant 16). For this reason, some reported that a barrier to participate in the SS program was the fact that their closest or preferred fitness center was not among the list of participating SS centers. But participants did value having access to inexpensive or free exercise programs. In fact, a few participants expressed a desire to use the EF or SS programs, but were unable to do so because their health care plan did not offer free enrollment. Furthermore, it was important for participants to have access to a range of fitness classes that would suit people of varying ages, fitness levels, and personal preferences. This was expressed by contrasting perspectives. "There are a lot of classes offered that are group exercise classes, but the ones that were for seniors, I found too easy" (participant 49), was a perspective shared by some participants. On the other hand, 
many participants were discouraged by a class "where [the instructor] exhausted everybody so quickly that people just kind of fell down around her, and she didn't really even notice" (participant 24). Similarly, one individual desired more variation in the EF fitness classes, rather than repeating the same exercises every session. Some people also expressed interest in seeing new classes covered by EF or SS programs, such as yoga or classes focusing on sports conditioning, as many participants reported.

While the above issues were important factors in determining utilization of the EF and SS programs among current or everusers, by far the most prominent barrier to program utilization among the never-users was lack of adequate information. Many participants had simply never heard of one or both of these programs. Few reported hearing of these programs from their health care providers, and neither paper mailings nor information online had reached the entire target audience. A few individuals had seen these programs mentioned in the mailings, but admitted that they needed frequent reminders before taking the initiative to enroll in the program and attend. And, for those who had heard of one or both programs but were not regular users, there was confusion about which fitness facilities offered which program and how more information on the logistics of the program could be obtained. This was particularly true among participants who felt inexperienced at searching for information on the internet. Many participants felt it would be helpful, therefore, for health care systems to provide frequent information and other PA-promoting tools through a variety of mediums, and to encourage physicians to inform patients about the PA programs promoted by their health care system.

\section{Discussion}

This study aimed to explore the barriers to and facilitators of PA in general, and utilization of the EF and SS programs specifically, among older adults. To that end, we conducted focus group discussions with a sample of Group Health Medicare beneficiaries. Results showed that a variety of individual, interpersonal, environment, and community level barriers and facilitators influenced PA behavior, fitting well with the social-ecological model. ${ }^{28-30,32}$ We also observed interactions between different levels of influence. For example, several participants with prominent health concerns (an intrapersonal factor) were able to be more active when the built or social environment supported them (environmental and interpersonal factors).

Health conditions were a prominent theme among this group due to their role as both an impediment to and a motivator for PA and program participation. These results were in agreement with many others studies that also indicate that health is a strong predictor of activity levels..$^{20-23,33-35}$ It is clear that people become cognizant of their age-related physical limitations, and their awareness radiates into a lack of confidence in their abilities (ie, reduced self-efficacy ${ }^{36,37}$ ); uncertainty about what activities are safe; and fear of injury, pain, overexertion, or prolonged recovery. For this reason, lack of professional guidance, as well as feeling unaccustomed or unmotivated by exercise for the sake of exercise, served as major barriers to PA in general. Barriers to PA program use specifically included dislike for gyms and group activities, lack of motivating instructors, program eligibility criteria, limited awareness about programs, and programs not meeting desired fitness goals and needs. Interestingly, lack of time, which was noted in some other qualitative studies and more often in quantitative studies, ${ }^{20,21}$ was not mentioned as a barrier to either PA in general or program utilization among these participants.

Overall, we found that having free or inexpensive access to fitness facilities and classes through the EF and SS programs was a motivator, but often more incentive was needed to get people to enroll and participate regularly in the programs. For some, individual preferences for group-based exercise, enjoyment of the social aspect of classes, and encouragement and companionship from others were factors that allowed them to stay active or start using one of the PA programs. Other important motivating factors for program utilization included having instructors who were engaging and welltrained to work with older adults' bodies and being able to attend their preferred and the most conveniently located fitness facility through the programs. Suggestions from those who were unaware of the SS and EF programs or who were in some way excluded from the free or low-cost access to the programs indicated that program utilization may increase if eligibility criteria were expanded and distribution of information about the programs were more thorough and frequent.

A key finding from our study was that older adults do want their health care providers and health care systems to support their PA. For example, they wanted their health care system to provide more and frequent information about available PA programs and other safe PA options. They also wanted further supervision from their physician or another provider (eg, physical therapist), as discussions of PA in office visits were rare and seldom, if ever, followed up in subsequent visits. Participants expressed interest in having health care professionals help them safely start a PA routine, set realistic PA goals, track PA progress, and work through the health and age-related barriers they face in being active. These forms of support could all help foster a stronger sense of selfefficacy ${ }^{37,38}$ and the belief in one's ability to perform PA. ${ }^{36,37}$ Self-efficacy is an important facilitator, as well as an outcome, of both initiating and maintaining PA, ${ }^{37-39}$ but it may decline with age due to the manifestation of physical limitations and disabilities. ${ }^{37,38,40}$ Thus, older adults may particularly benefit from regular verbal encouragement, recognition of performance successes, and help with interpretation of their physical and affective PA experiences. ${ }^{37-39}$

A few recent, randomized controlled trials have indicated that PA recommendations and follow-up counseling from primary care physicians and health educators may impact older patients' PA levels. ${ }^{41-43}$ The effects observed in these studies 
are often small, and it is unknown whether the effects are long-lasting. Still, the fact that most of our participants, regardless of whether they enjoyed PA or not, recognized that PA plays an important role in both physical and mental health demonstrates an important opportunity for trained health professionals to offer concrete support and guidance. Health professionals are uniquely positioned to dispel misconceptions about exercise (eg, deep venous thrombosis as a barrier to stair and hill climbing). They are also uniquely positioned to encourage specific forms of exercise to address older adults' fears (eg, teaching functional strength and balance exercises to reduce risk and fear of falling). Moreover, because older adults tend to make frequent health care visits, ${ }^{12}$ the health care system is an ideal context in which to focus educational and self-efficacy-promoting interventions among this demographic.

Other ways health care systems may further promote PA among older adults include the following. First, it was clear that accessibility, cost, and convenience of PA programs are important for older adults. Our focus group discussions revealed that it is important for the EF, SS, and any similar PA programs to be made accessible to all older adults, regardless of Medicare membership. Second, incorporating more fitness facilities in the SS program or similar programs that offer gym membership to older adults may encourage increased participation by allowing members access to the program through the most conveniently located or preferred fitness center. Third, PA programs need to be tailored to a range of abilities, either by offering different classes for varying fitness levels or having instructors who are able to demonstrate modified versions of exercises so that a given class holds appeal both to those looking for more of a challenge and those able to handle only light activity. Fourth, health plans may benefit from exploring ways to collaborate with senior fitness centers, walking groups, the Mountaineers, or other programs designed to promote PA among older adults in order to enhance the range of options available for those who are more motivated by group-based activities.

Finally, for those who are unaccustomed to or simply dislike exercise for the sake of exercise, it is important for health care systems and providers to emphasize that PA can also be achieved through daily household activities (eg, mowing the lawn, gardening, etc.) or walking to accomplish daily tasks (eg, walking to the store instead of driving, walking the dog). Recent intervention studies have suggested that incorporating regular PA into everyday routines may offer some of the same benefits for fitness and health as structured PA programs. ${ }^{44,45}$ For this reason, health plans could provide coverage of PA programs, such as Active Living Every Day and Active Choices, which offer either group-based or one-on-one counseling to support PA through daily activities. ${ }^{46,47}$

Study limitations include that our focus groups were primarily Caucasian and relatively well-educated. ${ }^{48}$ Though these demographics appear to be common among other PA studies that rely on volunteer participation ${ }^{4-52}$ and are representative of the racial/ethnic profile of King County and Washington State, ${ }^{53}$ these sample characteristics may limit the generalizability of our study. PA levels are estimated to be lower on average among some racial/ethnic minorities when using self-report data, ${ }^{4,54-57}$ though this is not necessarily the case when comparing accelerometer-measured PA levels. ${ }^{7}$ Higher education levels also tend to be associated with greater PA. ${ }^{55-57}$ The relative importance of the barriers to and facilitators of PA identified in our sample may, therefore, vary from those of more racially and ethnically diverse groups or those from broader educational and socioeconomic backgrounds. For example, we may have failed to capture themes relating to time constraints, competing obligations (eg, caregiving responsibilities), and cultural barriers and enablers that may be more prominent among other subpopulations. ${ }^{33,55,56,58}$ Nonetheless, it is reassuring that many of the barriers and facilitators that emerged in our study, including issues of chronic health conditions, health benefits, neighborhood safety, social support, self-efficacy, and program/facility affordability and accessibility, are reportedly common themes across diverse populations in the United States. ${ }^{33,55,56,58}$

A further limitation to the generalizability of our study is the high activity level of our participants relative to the general older adult population. ${ }^{4,7}$ Barriers and motivators to PA and PA program utilization may differ between those who are already more active and those who are sedentary, though our final list of barriers and motivators was not dissimilar from that of another qualitative study that distinguished between inactive and active participants. ${ }^{20}$ The reported activity levels among our sample may in part be an overestimate-a wellknown limitation of the IPAQ instrument. ${ }^{59-61}$ Additionally, the very nature of the focus group topic may have attracted participants who are relatively more aware of and motivated by their knowledge of the importance of PA. However, we did have a number of people who did not meet PA guidelines and whose opinions were represented in our results. Moreover, the fact that the need for greater provider and health care systems support emerged as an important topic among this relatively active group suggests that the need for support and guidance will be that much more critical for boosting PA among sections of the population that may be more sedentary or less motivated by existing efforts to encourage PA.

\section{Conclusion}

Using the social-ecological model as our theoretical framework, we presented a set of prominent factors that merit consideration by health care professionals and organizations interested in PA promotion and programming. Our results highlight the fact that the process of engaging in PA and using PA programs is layered in a network of personal, social, environmental, and structural barriers and facilitators. Efforts to increase national PA levels among older adult populations will, therefore, require multilevel interventions that address individual, community, and organizational level factors. 
We identified a number of important ways that the health care system can be involved in promoting PA among older adults. Specifically, older adults would benefit from having prepared, proactive providers who are equipped with the appropriate resources and knowledge to offer support, counseling, and follow-up; receiving professional, individually tailored guidance on safe exercises; and being reminded periodically about the logistics and benefits of available PA programs and options. PA program planning should consider the wide range of fitness levels, self-motivation, and personal preferences; this could include designing more varied programs, having instructors that are knowledgeable and can engage and make modifications for different participants, and offering counseling on alternative means to incorporating PA into daily lifestyle routines.

\section{References}

1. Chodzko-Zajko W, Schwingel A, Park CH. Successful aging: the role of physical activity. Am J Lifestyle Med 2009;3:20-28.

2. American College of Sports Medicine, Chodzko-Zajko WJ, Proctor DN, Fiatarone Singh MA, Minson CT, Nigg CR, Salem GJ, Skinner JS. American College of Sports Medicine position stand. Exercise and physical activity for older adults. Med Sci Sports Exerc 2009;41:1510-1530.

3. Physical Activity Guidelines Advisory Committee. Physical activity guidelines advisory committee report, 2008. Washington, DC: U.S. Department of Health and Human Services; 2008.

4. Carlson SA, Fulton JE, Schoenborn CA, Loustalot F. Trend and prevalence estimates based on the 2008 physical activity guidelines for Americans. Am J Prev Med 2010;39:305-313.

5. Nelson ME, Rejeski WJ, Blair SN, Duncan PW, Judge JO, King AC, Macera CA, Castaneda-Sceppa C. Physical activity and public health in older adults: recommendation from the American College of Sports Medicine and the American Heart Association. Med Sci Sports Exerc 2007;39: 1435-1445.

6. Centers for Disease Control and Prevention (CDC). Vital signs: walking among adults--United States, 2005 and 2010. MMWR Morb Mortal Wkly Rep 2012;61:595-601.

7. Troiano RP, Berrigan D, Dodd KW, Mâsse LC, Tilert T, McDowell M. Physical activity in the United States measured by accelerometer. Med Sci Sports Exerc 2008;40:181-188.

8. Lee IM, Shiroma EJ, Lobelo F, Puska P, Blair SN, Katzmarzyk PT. Effect of physical inactivity on major non-communicable diseases worldwide: an analysis of burden of disease and life expectancy. Lancet 2012;380:219-229.

9. Anderson LH, Martinson BC, Crain AL, Pronk NP, Whitebird RR, O'Connor PJ, Fine LJ. Health care charges associated with physical inactivity, overweight, and obesity. Prev Chronic Dis 2005;2:A09.

10. Mokdad AH, Bowman BA, Ford ES, Vinicor F, Marks JS, Koplan JP. The continuing epidemics of obesity and diabetes in the United States. JAMA 2001;286:1195-1200.

11. Wang G, Pratt M, Macera C, Zheng Z-J, Heath G. Physical activity, cardiovascular disease, and medical expenditures in U.S. adults. Ann Behav Med 2004;28:88-94.

12. U.S. Department of Health and Human Services. A profile of older Americans: 2011. Washington, DC: U.S. Department of Health and Human Services, Administration on Aging, Administration on Community Living; 2011.

13. Vincent GK, Velkoff VA. The next four decades: The older population in the United States: 2010 to 2050. Washington, DC: U.S. Department of Commerce, Economics and Statistics Administration, U.S. Census Bureau; 2010.
14. Belza B, Shumway-Cook A, Phelan EA, Williams B, Snyder SJ, LoGerfo JP. The effects of a community-based exercise program on function and health in older adults: the EnhanceFitness program. J Appl Gerontol 2006;25:291-306.

15. Wallace JI, Buchner DM, Grothaus L, Leveille S, Tyll L, LaCroix AZ, Wagner EH. Implementation and effectiveness of a community-based health promotion program for older adults. J Gerontol A Biol Sci Med Sci 1998;53A:M301M306.

16. Ackermann RT, Cheadle A, Sandhu N, Madsen L, Wagner EH, LoGerfo JP. Community exercise program use and changes in healthcare costs for older adults. Am J Prev Med 2003;25:232-237.

17. Nguyen HQ, Ackermann RT, Maciejewski M, Berke E, Patrick M, Williams B, LoGerfo JP. Managed-Medicare health club benefit and reduced health care costs among older adults. Prev Chronic Dis 2008;5:A14.

18. Nguyen HQ, Ackermann RT, Berke EM, Cheadle A, Williams B, Lin E, Maciejewski ML, LoGerfo JP. Impact of a managed-medicare physical activity benefit on health care utilization and costs in older adults with diabetes. Diabetes Care 2007;30:43-48.

19. Nguyen HQ, Maciejewski ML, Gao S, Lin E, Williams B, LoGerfo JP. Health care use and costs associated with use of a health club membership benefit in older adults with diabetes. Diabetes Care 2008;31:1562-1567.

20. Costello E, Kafchinski M, Vrazel J, Sullivan P. Motivators, barriers, and beliefs regarding physical activity in an older adult population. J Geriatr Phys Ther 2011;34:138-147.

21. Baert V, Gorus E, Mets T, Geerts C, Bautmans I. Motivators and barriers for physical activity in the oldest old: a systematic review. Ageing Res Rev 2011;10:464-474.

22. van Stralen MM, De Vries H, Mudde AN, Bolman C, Lechner L. Determinants of initiation and maintenance of physical activity among older adults: a literature review. Health Psychol Rev 2009;3:147-207.

23. Bauman AE, Reis RS, Sallis JF, Wells JC, Loos RJF, Martin BW; Lancet Physical Activity Series Working Group. Correlates of physical activity: why are some people physically active and others not? Lancet 2012;380:258-271.

24. Craig CL, Marshall AL, Sjostrom M, Bauman AE, Booth ML, Ainsworth BE, Pratt M, Ekelund U, Yngve A, Sallis JF, Oja P. International physical activity questionnaire: 12-country reliability and validity. Med Sci Sports Exerc 2003;35: 1381-1395.

25. Guidelines for data processing and analysis of the international physical activity questionnaire (IPAQ) — Short and long forms. 2005. Available at: http://www.ipaq.ki.se/scoring.pdf. Accessed July 28, 2013.

26. Ware JE Jr., Sherbourne CD. The MOS 36-item short-form health survey (SF-36): I. Conceptual framework and item selection. Med Care 1992;30:473-483.

27. Boyatzis RE. Transforming qualitative information: thematic analysis and code development. Thousand Oaks, CA: Sage Publications; 1998.

28. Sallis JF, Owen N, Fisher EB. Ecological models of health behavior. In: Glanz K, Rimer BK, Viswanath K, eds. Health behavior and health education: theory, research, and practice. 4th ed. San Francisco, CA: Jossey-Bass; 2008. 465-486.

29. McLeroy KR, Bibeau D, Steckler A, Glanz K. An ecological perspective on health promotion programs. Health Educ Behav 1988;15:351-377.

30. Stokols D. Translating social ecological theory into guidelines for community health promotion. Am J Health Promot 1996;10:282-298.

31. U.S. Department of Health and Human Services. 2008 Physical Activity Guidelines for Americans. Washington, DC: U.S. Department of Health and Human Services; 2008. 
32. Sallis JF, Cervero RB, Ascher W, Henderson KA, Kraft MK, Kerr J. An ecological approach to creating active living communities. Annu Rev Public Health 2006;27:297-322.

33. Belza B, Walwick J, Shiu-Thornton S, Schwartz S, Taylor M, LoGerfo J. Older adult perspectives on physical activity and exercise: voices from multiple cultures. Prev Chronic Dis 2004;1:A409.

34. Moschny A, Platen P, Klaassen-Mielke R, Trampisch U, Hinrichs T. Barriers to physical activity in older adults in Germany: a cross-sectional study. Int J Behav Nutr Phys Act 2011;8:121.

35. Schutzer KA, Graves BS. Barriers and motivations to exercise in older adults. Prev Med 2004;39:1056-1061.

36. Bandura A. Self-efficacy: the exercise of control. New York: W.H. Freeman; 1997.

37. McAuley E, Szabo A, Gothe N, Olson EA. Self-efficacy: Implications for physical activity, function, and functional limitations in older adults. Am J Lifestyle Med 2011;5: 361-369.

38. Lee LL, Arthur A, Avis M. Using self-efficacy theory to develop interventions that help older people overcome psychological barriers to physical activity: a discussion paper. Int J Nurs Stud 2008;45:1690-1699.

39. McAuley E, Jerome G, Marquez D, Elavsky S, Blissmer B. Exercise self-efficacy in older adults: social, affective, and behavioral influences. Ann Behav Med 2003;25:1-7.

40. Grembowski D, Patrick D, Diehr P, Durham M, Beresford S, Kay E, Hecht J. Self-efficacy and health behavior among older adults. J Health Soc Behav 1993;34:89-104.

41. Ackermann RT, Deyo RA, LoGerfo JP. Prompting primary providers to increase community exercise referrals for older adults: a randomized trial. J Am Geriatr Soc 2005;53:283-289.

42. Pinto BM, Goldstein MG, Ashba J, Sciamanna CN, Jette A. Randomized controlled trial of physical activity counseling for older primary care patients. Am J Prev Med 2005;29: 247-255.

43. Grandes G, Sanchez A, Sanchez-Pinilla RO, Torcal J, Montoya I, Lizarraga K, Serra J; PEPAF Group. Effectiveness of physical activity advice and prescription by physicians in routine primary care: a cluster randomized trial. Arch Intern Med 2009;169:694-701.

44. Dunn AL, Marcus BH, Kampert JB, Garcia ME, Kohl HW 3rd, Blair SN. Comparison of lifestyle and structured interventions to increase physical activity and cardiorespiratory fitness: a randomized trial. JAMA. 1999;281:327-334.

45. King AC, Baumann K, O'Sullivan P, Wilcox S, Castro C. Effects of moderate-intensity exercise on physiological, behavioral, and emotional responses to family caregiving: a randomized controlled trial. J Gerontol A Biol Sci Med Sci 2002;57:M26-M36.

46. Wilcox S, Dowda M, Leviton LC, Bartlett-Prescott J, Bazzarre T, Campbell-Voytal K, Carpenter RA, Castro CM, Dowdy D, Dunn AL, Griffin SF, Guerra M, King AC, Ory MG, Rheaume C, Tobnick J, Wegley S. Active for Life: final results from the translation of two physical activity programs. Am J Prev Med 2008;35:340-351.

47. Wilcox S, Dowda M, Wegley S, Ory MG. Maintenance of change in the Active-for-Life initiative. Am J Prev Med 2009;37:501-504.

48. U.S. Department of Commerce. United States Census Bureau. Educational Attainment in the United States: 2012-Detailed Tables. 2012. Available at: http://www.census.gov/hhes/ socdemo/education/data/cps/2012/tables.html. Accessed July 28, 2013.

49. van der Bij AK, Laurant MGH, Wensing M. Effectiveness of physical activity interventions for older adults: a review. Am J Prev Med 2002;22:120-133.
50. McAuley E, Blissmer B, Katula J, Duncan TE, Mihalko SL. Physical activity, self-esteem, and self-efficacy relationships in older adults: a randomized controlled trial. Ann Behav Med 2000;22:131-139.

51. Wilcox S, Dowda M, Griffin SF, Rheaume C, Ory MG, Leviton L, King AC, Dunn A, Buchner DM, Bazzarre T, Estabrooks PA, Campbell-Voytal K, Bartlett-Prescott J, Dowdy D, Castro CM, Carpenter RA, Dzewaltowski DA, Mockenhaupt R. Results of the first year of active for life: translation of 2 evidence-based physical activity programs for older adults into community settings. Am J Public Health 2006;96: 1201-1209.

52. Griffin SF, Wilcox S, Ory MG, Lattimore D, Leviton L, Castro C, Carpenter RA, Rheaume C. Results from the Active for Life process evaluation: program delivery fidelity and adaptations. Health Educ Res 2010;25:325-342.

53. Washington State Office of Financial Management. Population by race and Hispanic Origin, 2000 and 2010. Available at: http://www.ofm.wa.gov/pop/asr/default.asp. Accessed July 29, 2013.

54. Centers for Disease Control and Prevention. U.S. Physical Activity Data and Statistics. Available at: http://www.cdc. gov/physicalactivity/data/. Accessed July 28, 2013.

55. Wilcox S, Castro C, King AC, Housemann R, Brownson RC. Determinants of leisure time physical activity in rural compared with urban older and ethnically diverse women in the United States. J Epidemiol Community Health 2000;54:667-672.

56. Eyler AE, Wilcox S, Matson-Koffman D, Evenson KR, Sanderson B, Thompson J, Wilbur J, Rohm-Young D. Correlates of physical activity among women from diverse racial/ethnic groups. J Womens Health Gend Based Med 2002;11:239-253.

57. Crespo CJ, Smit E, Andersen RE, Carter-Pokras O, Ainsworth BE. Race/ethnicity, social class and their relation to physical inactivity during leisure time: results from the Third National Health and Nutrition Examination Survey, 1988-1994. Am J Prev Med 2000;18:46-53.

58. Mathews AE, Laditka SB, Laditka JN, Wilcox S, Corwin SJ, Liu R, Friedman DB, Hunter R, Tseng W, Logsdon RG. Older adults' perceived physical activity enablers and barriers: a multicultural perspective. J Aging Phys Act 2010;18:119-140.

59. Lee PH, Macfarlane DJ, Lam T, Stewart SM. Validity of the International Physical Activity Questionnaire Short Form (IPAQ-SF): a systematic review. Int J Behav Nutr Phys Act 2011;8:115

60. Ekelund U, Sepp H, Brage S, Becker W, Jakes R, Hennings M, Wareham NJ. Criterion-related validity of the last 7-day, short form of the International Physical Activity Questionnaire in Swedish adults. Public Health Nutr 2006;9:258-265.

61. Rzewnicki R, Vanden Auweele Y, De Bourdeaudhuij I. Addressing overreporting on the International Physical Activity Questionnaire (IPAQ) telephone survey with a population sample. Public Health Nutr 2003;6:299-305.

\section{Author Affiliations}

Hilary J. Bethancourt, MA*, ,*; Dori E. Rosenberg, PhD, $M P H^{\dagger}$, ; Tara Beatty, $M A^{\S}$; David E. Arterburn, MD, $M P H^{\S}$

${ }^{*}$ University of Washington, Department of Anthropology; Seattle, $W A$

University of Washington, School of Public Health, Seattle, WA 
*University of Washington, Center for Studies in

Demography and Ecology (CSDE), Seattle, WA

${ }^{\S}$ Group Health Research Institute, Seattle, WA

\section{Appendix A: Focus Group Protocol}

Focus groups began with asking people to introduce themselves and tell us what kinds of physical activity they most enjoyed or, if they didn't do any physical activity, their favorite activity in general. Introductions were followed by discussions on the following six questions.

\section{Main Topic Questions:}

1. When considering all the things you do on a daily basis, how important is getting physical activity?

2. What can Group Health do to support you in maintaining or starting to do more physical activity?

3. One thing Group Health does for most of its Medicare members is encourage people to use the covered benefit to attend EnhanceFitness or Silver Sneakers programs. These are exercise programs offered all over the area. They are no cost to most Medicare members. Silver Sneakers allows you to use a fitness facility like the YMCA to have a workout. EnhanceFitness is a group based exercise class offered all over Seattle at Group Health clinics, senior centers and other locations. What do you think about the EnhanceFitness/Silver Sneakers benefit?

4. Would you be interested in using technology to help you track and to improve your physical activity? By technology I mean a cell phone app, a device like a pedometer, or a website.

5. Who would you want to help you be more active and how could they be most helpful?

6. If we were developing a program to help you be more active, would you want it to just target physical activity, or would you want to it address other things such as overall wellness, nutrition, and healthy aging? 